\title{
INFLUÊNCIA DOS PROCESSOS DIAGENÉTICOS NA POROSIDADE DOS ARENITOS DA FORMAÇÃO IBOREPI, BACIA DE LAVRAS DA MANGABEIRA, ESTADO DO CEARÁ
}

\author{
Zenilda Vieira Batista ${ }^{1}$; Mário Ferreira de Lima \\ Filho²; Wilson Rodrigues de Andrade Freitas $^{3}$; \\ Marcela Marques Vieira ${ }^{4}$; Sonia Maria Oliveira \\ Agostinho da Silva ${ }^{5}$, Valdielly Larisse Silva ${ }^{6}$
}

${ }^{1}$ Doutora em Geociências, Centro de Tecnologia, Engenharia de Petróleo (UFAL), Maceió/AL, Brasil.

ORCID: https://orcid.org/0000-0002-4535-7842

E-mail: zenilda.batista@ctec.ufal.br

${ }^{2}$ Doutor em Geociências, Centro de Tecnologia e Geociências, Departamento de Geologia (UFPE), Recife/PE, Brasil.

ORCID: https://orcid.org/0000-0002-8523-3457

E-mail: mflf@ufpe.br

${ }^{3}$ Mestre em Geociências, Centro de Tecnologia e Geociências, Departamento de Geologia (UFPE), Recife/PE, Brasil.

ORCID: https://orcid.org/0000-0002-8624-0122

E-mail: wrafreitas@gmail.com

${ }^{4}$ Doutora em Geociências, Centro de Ciências Exatas, Departamento de Geologia (UFRN), Natal/RN, Brasil. ORCID: https://orcid.org/0000-0003-2026-2098

E-mail: marcela@geologia.ufrn.br

${ }^{5}$ Doutora em Geologia, Centro de Tecnologia e Geociências, Departamento de Geologia (UFPE), Recife/PE, Brasil.

ORCID: https://orcid.org/0000-0003-3900-5741

E-mail:sonia@ufpe.br

${ }^{6}$ Mestre em Geociências, Centro de Tecnologia e Geociências, Departamento de Geologia (UFPE), Recife/PE, Brasil.

ORCID: https://orcid.org/0000-0002-6020-8386

E-mail: vallarisse@gmail.com

\section{Resumo}

O estudo diagenético é essencial para avaliar o potencial de arenitos como bons reservatórios de petróleo, gás e água. A diagênese dos arenitos da Formação Iborepi (Bacia de Lavras da Magabeira) é pouco conhecida, principalmente quanto a seu impacto sobre a porosidade original dessas rochas, que podem ser estudadas como análogos de reservatórios de bacias petrolíferas e aquíferos. A fim de conhecer os processos diagenéticos que afetaram os arenitos Iborepi, bem como seu potencial para armazenamento de fluidos, foram analisadas nove lâmenas delgadas. Esse estudo revelou que os processos diagenéticos que mais afetaram a porosidade primária desses arenitos e sua qualidade como reservatórios foram a compactação, cimentaço e a infiltração de argila, sendo a compactação predominante. Esses processos foram responsáveis pelo dano na porosidade e permeabilidade dessas rochas, face à redução do espaço poroso e obliteração da garganta de poros. A composição detrítica também influenciou na alteração da porosidade original, facilitaando a atuação de alguns processos diagnéticos. Embora essas rochas tenham uma porosidade razoável para armazenamento de fluidos (média de 14\%), suas heterogeneidades diagenéticas impactaram sua qualidade como reservatório.

Palavras-chave: Diagênese de Arenitos; Porosidade; Reservatório.

\section{INFLUENCE OF DIAGENETIC DEPOSITS ON THE POROSITY OF SANDSTONES FROM IBOREPI FORMATION, LAVRAS DA MANGABEIRA BASIN}

Abstract
The study of diagenetic processes is essential to evaluate the
potential of sandstones as good reservoirs of oil, gas, and water.
Nonetheless, the diagenesis of the Iborepi Formation sandstones
(Lavras da Mangabeira Basin) is little known, mainly regarding
its effect on the original porosity of these rocks, which can be
studied as analogs of oil basin reservoirs. Aiming to evaluate the
diagenetic process that affected the Iborepi sandstones, as well as
their potential for fluid storage, nine thin sections were analyzed.
The study revealed that the processes that most affected the
primary porosity of these rocks and their quality as reservoirs
include compaction, cementation, and clay infiltration, with
compaction prevailing. These processes have damaged the
porosity and permeability of these rocks by reducing pore space
and clogging pore throats. The detritic composition has also
affected the original porosity, favoring some diagenetic
processes. Although these rocks have a reasonable porosity for


fluid storage (14\% average), their diagenetic heterogeneities have impacted their quality as reservoirs.

Keywords: Sandstones Diagenesis; Porosity; Reservoir.

\section{INFLUENCIA DE LOS PROCESOS DIAGENÉTICOS EN LA POROSIDAD DE LAS ARENAS DE LA FORMACIÓN IBOREPI, CUENCA LAVRAS DA MANGABEIRA, ESTADO DE CEARÁ}

\section{Resumen}

El estudio diagenético es fundamental para evaluar el potencial de las areniscas como buen indicador de reservorio petrolíferos. La diagénesis de las areniscas de la Formación Iborepi (Cuenca Lavras da Mangabeira) es poco conocida, especialmente en lo que respecta a su impacto en la porosidad original de estas rocas, que pueden ser estudiadas como análogas de los reservorios en cuencas petrolíferas y acuíferas. Para conocer los procesos diagenéticos que afectaron a las areniscas de Iborepi, así como el potencial de estas rocas para el almacenamiento de fluidos, se analizaron nueve laminas delgadas. Este estudio reveló que los procesos diagenéticos que más afectaron la porosidad primaria de estas areniscas y su calidad como reservorios fueron la compactación, cementación e infiltración de arcilla, siendo la compactación predominante. Estos procesos fueron responsables del daño a la porosidad y permeabilidad debido a la reducción del espacio poroso y la obliteración de la garganta de los poros. La composición detrítica también influyó en la alteración de la porosidad original, facilitando la realización de algunos procesos diagnósticos. Aunque estas rocas tienen una porosidad razonable para el almacenamiento de fluidos (promedio de 14\%), sus heterogeneidades diagenéticas impactaron su calidad como reservorio.

Palabras claves: Diagénesis Areniscas; Porosidad; Reservorio.

\section{INTRODUÇÃO}

Entender a diagênese e seus processos é essencial para avaliar a qualidade de arenitos como reservatórios de petróleo, gás e água, visto que a diagênese exerce controle na porosidade e na permeabilidade da rocha e, consequentemente, no armazenamento de hidrocarbonetos (ROSSI et al., 2001; ALRAMADAN et al., 2005) e água subterrânea.

Diversos processos diagenéticos afetam reservatórios de hidrocarbonetos (MORAES \& SURDAM, 1993). É por isso que o seu estudo tem se tornado uma ferramenta fundamental para compreender seus impactos na qualidade de reservatório. Os constituintes diagenéticos podem aumentar, preservar ou obstruir a porosidade, prejudicando a permeabilidade dos reservatórios a partir de um complexo arranjo de parâmetros inter-relacionados (POSAMENTIER \& ALLEN, 1999; MORAD et al., 2012).

Segundo Worden et al (2018), para estabelecer os controles dominantes na qualidade do reservatório é fundamental definir os constituintes, textura, composição mineralógica, fábrica, morfologia do cimento e tipos de poros.

A Formação Iborepi, objeto desse estudo, faz parte da Bacia Sedimentar de Lavras da Mangabeira, localizada no sudeste do Estado do Ceará. Estudos recentes (Queiroz et al., 2017; Batista et al., 2018) têm contribuído para o conhecimento sobre a composição dos arenitos dessa formação. A petrologia e petrografia desta unidade, porém, é pouco conhecida, principalmente no que diz respeito aos processos diagenéticos que atuaram sobre os arenitos.

Assim, o objetivo deste trabalho é identificar e avaliar, através de análise petrográfica, os processos diagenéticos que impactaram a porosidade original dos arenitos da Formação Iborepi. Entender a atuação desses processos é importante para avaliar o potencial dessas rochas como reservatórios de fluidos, especialmente de água subterrânea do Sistema Aquífero de Lavras da Mangabeira, constituído pelo Açude do Rosário, Bacias Hidrográficas de Varzea-Alegre, Sub-Bacia Hidrográfica do Salgado, e outros.

\section{CONTEXTO GEOLÓGICO REGIONAL}

A Bacia de Lavras da Mangabeira apresenta uma área total de aproximadamente $60,27 \mathrm{~km}^{2}$ e é formada por um conjunto de três pequenas bacias ou sub-bacias: Riacho do Meio (área aproximada de 33,2 km²); Riacho do Rosário $\left(24,8 \mathrm{~km}^{2}\right.$, e a Minibacia do Iborepi (2,2 $\left.\mathrm{km}^{2}\right)$ (GRANJEIRO et al., 2008). Essa bacia, juntamente com as bacias de Iguatu, Lima Campos, Rio do Peixe, Araripe, São José do Belmonte, Jatobá, entre outras, formam o conjunto de bacias interiores do Nordeste brasileiro, alinhadas segundo o Trend Cariri-Potiguar (NE-SW) (Figura 1). A origem e evolução dessas bacias estão associadas aos eventos tectônicos que causaram o rifteamento do Gondwana e abertura do Atlântico Sul (MATOS, 1992, 1999).

A ruptura do Gondwana promoveu a reativação de falhas préexistentes no embasamento pré-cambriano, o que condicionou a formação e o desenvolvimento de pequenas e grandes bacias sedimentares ao longo das margens atlânticas dos continentes Africano e Sul-americano (MATOS, 1992, 1999).

Dentre os modelos tectônicos propostos para explicar a evolução das bacias interiores, destacam-se os de distensão NW (MATOS, 1992, 1999). O modelo proposto sugere que a Zona de Cisalhamento Patos teria sua extremidade oeste terminada em uma série de falhas curvadas, formando uma geometria sigmoidal. No Neocomiano, uma distensão de direção NW-SE teria invertido as falhas que originalmente eram transpressionais para falhas normais, o que reativou pequenos segmentos da Zona de Cisalhamento Patos, originando assim, as Bacias interiores do Nordeste.

Na Zona Transversal da Província Borborema predominam alinhamentos estruturais de direção E-W que tendem para NESW, e é neste trecho de inflexão estrutural que estão implantadas as bacias sedimentares Lavras da Mangabeira (VERÍSSIMO \& AGUIAR, 2005).

A Bacia de Lavras da Mangabeira encontra-se sobre o embasamento pré-cambriano do Domínio Rio Piranhas e Faixa Seridó, ambos inseridos no Domínio Rio Grande do Norte da Província Borborema (BRITO NEVES et al., 2000). O registro sedimentar dessa bacia compreende três unidades estratigráficas pertencentes ao Grupo Lavras da Mangabeira: as formações Iborepi (unidade basal), Serrote do Limoeiro (unidade superior), e rochas basálticas (basalto de Lavras da Mangabeira). 

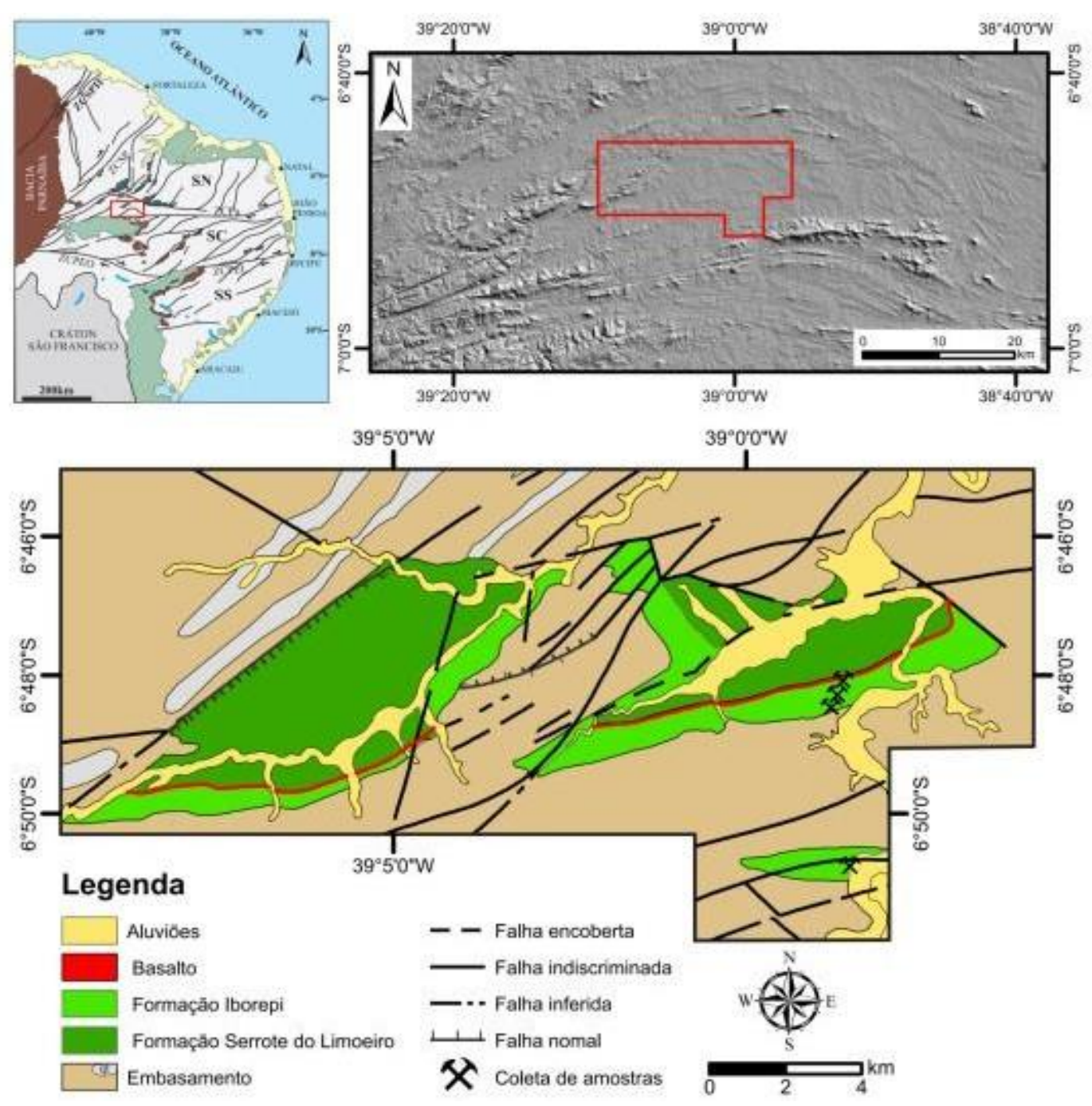

Figura 1 - A) Mapa das bacias sedimentares interiores do Nordeste do Brasil com destaque (retângulo em vermelho) para a Bacia de Lavras da Mangabeira (BLM)); B) Relevo sombreado (Modelo Digital de Terreno) da BLM; e C) Localização das bacias sedimentares de Lavras da Mangabeira e pontos de coleta de amostras de rocha. 1: Sub-baica de Riacho do Rosário; 2: Sub-bacia de Riacho do Meio; 3: Sub-bacia de Iborepi. Modificada de Assine (1992) e Veríssimo \& Aguiar (2005).

A Formação Iborepi é constituída por arenitos grossos a médios, siltitos e arenitos conglomeráticos pobremente selecionados, com grãos angulosos a subarredondados, maciços e com estratificação cruzada planar (Figura 2A e B). Batista (2015) associou essa formação a sistemas de leques aluviais e fluvial entrelaçado.

A Formação Serrote do Limoeiro é composta por arenitos médios a finos e siltitos bem selecionados, além de argilitos maciços com estratificação cruzada planar. Os basaltos de Lavras da Mangabeira ocorrem intercalados entre as formações Iborepi e Serrote do Limoeiro (Figura 3).

\section{METODOLOGIA}

\subsection{Materiais e Métodos}

Foram confeccionadas nove lâminas delgadas para caracterização petrográfica de amostras coletadas em três afloramentos da Fm. Iborepi, localizados na porção sul da Bacia Lavras da Mangabeira (Figura 1C). Essas lâminas foram impregnadas a vácuo com resina epóxy azul, conforme a técnica de Cesero et al. (1989), para melhor definir e caracterizar a porosidade ao Microscópio Óptico. 

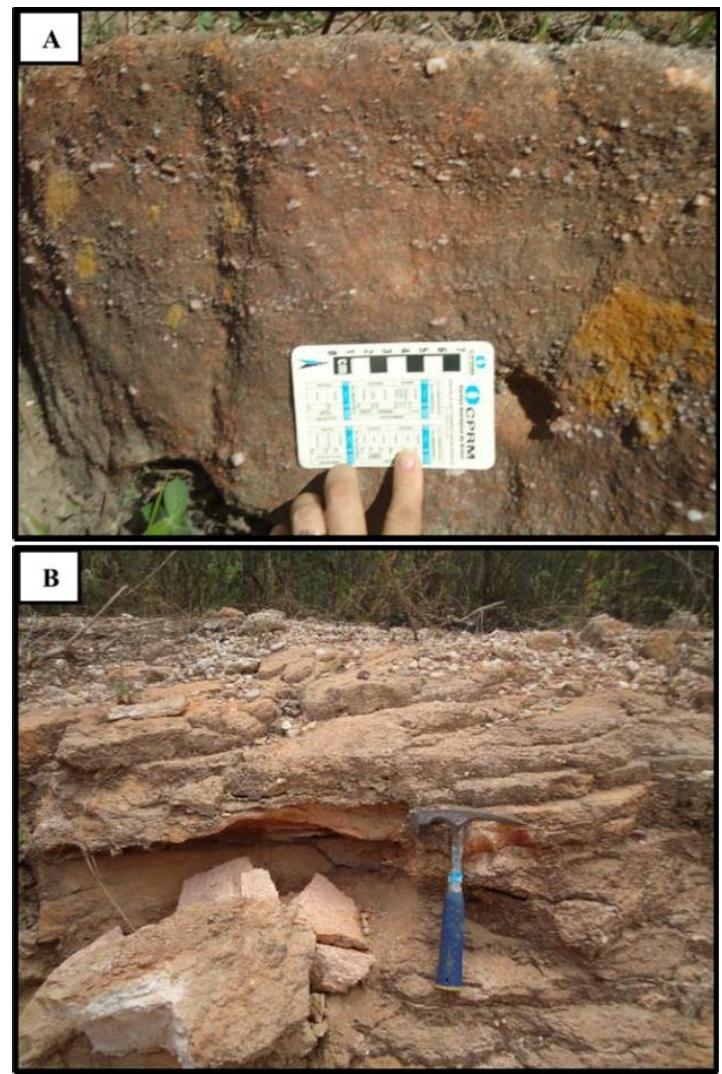

Figura 2 - Rochas da Formação Iborepi: A) Arenito conglomerático maciço, com níveis de seixos; B) Arenito grosso com estratificação cruzada planar (seta).

Descrições quantitativas e qualitativas foram feitas utilizando microscópio petrográfico modelo O600P Opticam, de luz transmitida e refletida com câmera digital acoplada. Três amostras foram analisadas em Microscópio Eletrônico de Varredura (MEV) acoplado a um Sistema de Detecção de Energia Dispersiva de Raios-X (EDS) e Dispersão de Comprimento de Ondas (WDS), Modelo SSX-550 (voltagem: 20kV) SHIMADZU; as amostras foram previamente metalizadas com ouro e carbono.

A microscopia óptica visou à identificação da composição mineralógica e à descrição de aspectos texturais, diagenéticos, contato entre os grãos e porosidade. Foram contados 300 pontos por lâmina (arcabouço, matriz, cimento e porosidade), como sugerido por Gazzi-Dicknson (cf. ZUFFA, 1985).

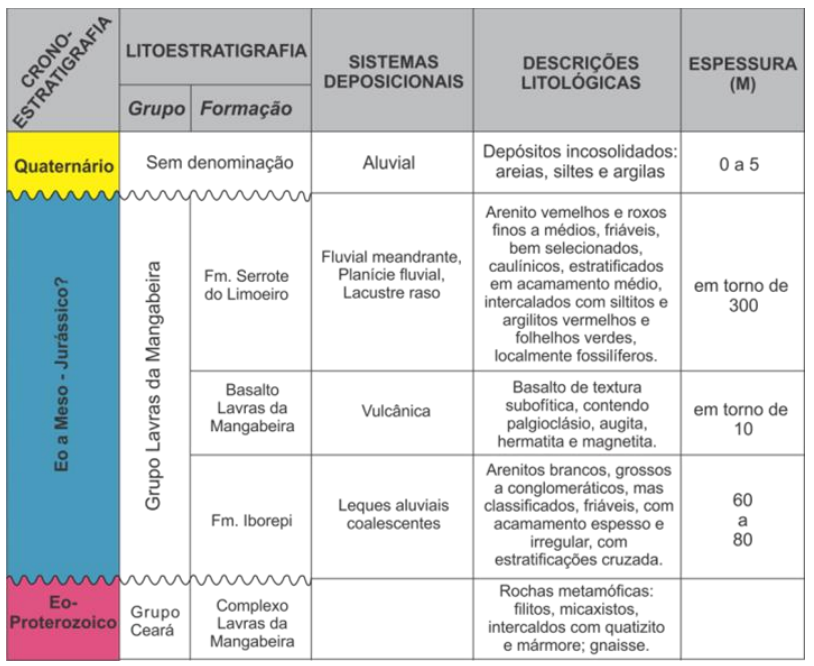

Figura 3 - Quadro estratigráfico da Bacia de Lavras da Mangabeira. Modificado de Ponte et al. (1990); Veríssimo \& Aguiar (2005).

A granulometria, arredondamento e seleção dos grãos foram analisadas segundo WENTWORTH (1922), TEIXEIRA et al. (2003), POWERS (1953) e LONGIARU (1987). Com relação à maturidade textural e mineralógica, essas foram definidas com base em Folk (1951, 1974) e Pettijohn (1975), respectivamente. Para análise da composição mineralógica dos grãos detríticos, foi utilizada a classificação de Folk (1968), com base no conteúdo total de quartzo, feldspato e fragmentos líticos.

Para identificar a mineralogia dos argilominerais, foi feita análise de Difratometria de Raios-X (DRX) em três amostras. Essa técnica permite a identificação qualitativa e semiquantitativa da mineralogia na fração $<2 \mu \mathrm{m}$, onde se concentram os argilominerais. As análises foram feitas no Laboratório de Raios$\mathrm{X}$ do Instituto de Tecnologia de Pernambuco. As amostras de rocha foram previamente pulverizadas com pistilo em um gral de ágata e depois peneiradas, usando uma peneira ABNT 200 mesh (abertura de $0.75 \mathrm{~mm}$ ). Foi utilizado um aparelho de difração de

Raios-X de marca Rigaku, modelo Ultima, operando com corrente de $20 \mathrm{~mA}$ e tensão de $40 \mathrm{kV}$, utilizando radiação K Alfa do cobre, com velocidade do goniômetro de $2^{\circ}$ por minuto. Foram realizadas varreduras entre $2 \theta=2^{\circ}$ e $2 \theta=100^{\circ}$ para as análises em amostras in natura e in natura aquecida a $500^{\circ} \mathrm{C}$ por 12 horas; também foram analisadas amostras com tratamento de glicolagem mediante varredura entre $2 \theta=2^{\circ}$ e $2 \theta=15^{\circ}$. O aquecimento e glicolagem foram realizadas para identificar os argilominerais do grupo de $12 \AA$ a $15 \AA$ (montmorilonita, clorita e vermiculita) e paligoskita, segundo os critérios de WARSHAW \& ROY (1961).

A porosidade da rocha é calculada através da razão entre o

volume de vazios (poros) e seu volume total, sendo a sua quantificação em seção delgada obtida por meio da análise modal e visual e apresentada em porcentagem. A porosidade média dos arenitos Iborepi foi obtida pela média aritmética das porosidades por seção delgada (GESICKI, et al., 2009).

O empacotamento das rochas foi determinado por meio do índice de Kahn (1956), que classifica o empacotamento como frouxo, normal e fechado. Este índice refere-se ao arranjo dos 
grãos entre si, com um arcabouço mais fechado ou mais aberto, dependendo da história de soterramento das rochas, e é representado em porcentagem.

\section{RESULTADOS E DISCUSSÃO}

\subsection{Aspectos Mineralógicos e Texturais}

Os arenitos da Formação Iborepi são compostos por quartzo $(\leq 64 \%)$, feldspatos $(\leq 5 \%)$, fragmentos líticos $(\leq 2 \%)$ e minerais acessórios $(<1 \%)$. O quartzo ocorre monocristalino (Figura 4A) e policristalino, sendo esse último mais frequente nos arenitos com granulometria mais grossa. O feldspato ocorre como microclínio, ortoclásio, plagioclásio e pertita (Figura 4B), frequentemente alterados por processos diagenéticos. Os fragmentos líticos são metamórficos (gnaisse e xisto) e sedimentares (chert, Figura 5A).
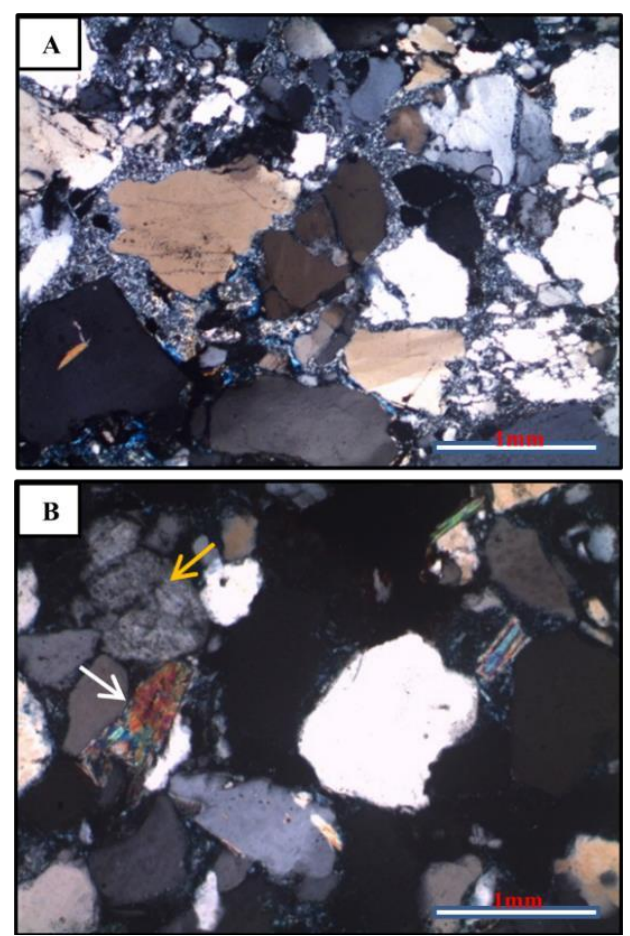

Figura 4 - Constituintes primários dos arenitos da Formação Iborepi: A) Grãos de quartzo monocristalino (PX); B) Feldspato microclínio fraturado e parcialmente alterado (seta laranja) $e$ muscovita entre grãos (seta branca, PX).

Os minerais acessórios incluem muscovita, opacos, biotita, zircão, turmalina e rutilo. Muscovita (Figura 4B) e biotita comumente ocorrem alteradas e substituídas por caulinita e clorita, respectivamente; turmalina e rutilo são menos comuns. Os argilominerais são a esmectita, ilita, caulinita, interestratificado de ilita/esmectita e traços de clorita autigênica (Figura 5B), com predominância dos dois primeiros.
Os arenitos da Fm. Iborepi são pobremente selecionados, com grãos variando entre angulosos a subarredondados, e com baixa esfericidade. Apresentam menos de 5\% de matriz deposicional e, em maior proporção, matriz argilosa infiltrada $(>5 \%)$. São texturalmente imaturos (Folk, 1974) e mineralogicamente maduros (PETTIJOHN, 1975).
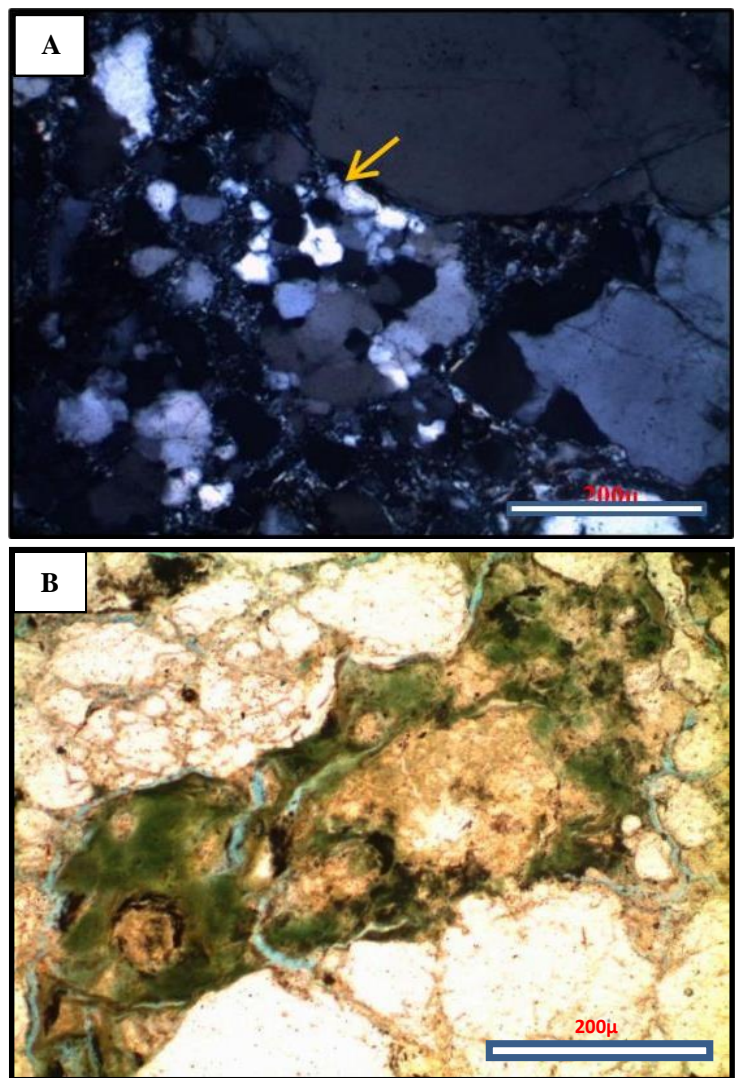

Figura 5 - Constituintes dos arenitos da Formação Iborepi: A) Fragmento lítico de chert (seta, PX); B) Clorita autigênica (seta, P//).

Essas rochas apresentam um arcabouço suportado pela matriz, com empacotamento normal e fechado (índice de Kanh, 1956), com $\mathrm{P}=42$ e $\mathrm{P}=56$, respectivamente. Os contatos são pontuais, retos, côncavo-convexos e suturados; os pontuais indicam profundidade rasa e baixa compactação (à medida que a profundidade aumenta, ocorre o soterramento progressivo dos grãos e mudança gradual dos contatos para longos, côncavoconvexos e suturados (BHUIYAN \& HOSSAIN, 2020)).

Com base em Folk (1968), os arenitos da Formação Iborepi foram classificados como quartzoarenitos subarcósio (Figura 6). 


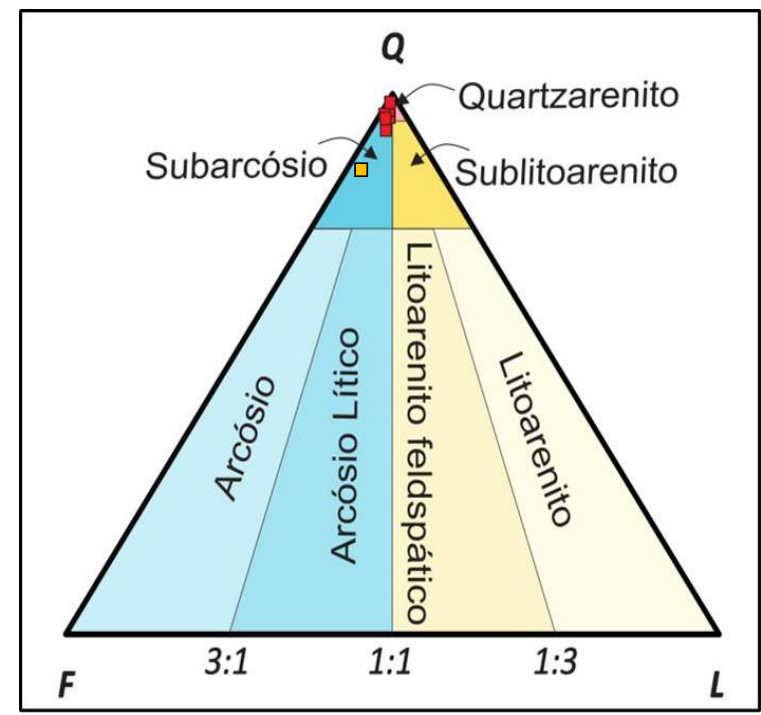

Figura 6 - Classificação composicional dos arenitos $d a$ Formação Iborepi, segundo Folk (1968).

\subsection{Porosidade e Compactação}

A maioria dos arenitos estudados apresenta empacotamento fechado indicando forte compactação, principalmente mecânica. Porém, em algumas amostras ocorre empacotamento normal, com maior porosidade, devido à menor influência da compactação. A porosidade média desses arenitos é de 14\% (Quadro 1), predominando a primária intergranular (Figura 7A). De forma subordinada ocorre porosidade secundária intragranular por dissolução e fraturas em grãos primários (Figura 7B e C).

Quadro 1 - Quadro com as porcentagens de porosidade de cada amostra analisada.

\begin{tabular}{|c|c|}
\hline Amostra & Porosity (\%) \\
\hline 1 & 20 \\
\hline 2 & 13 \\
\hline 3 & 11 \\
\hline 4 & 14 \\
\hline 5 & 13 \\
\hline 6 & 15 \\
\hline 7 & 15 \\
\hline 8 & 9 \\
\hline 9 & 18 \\
\hline \multicolumn{2}{|c|}{ Média Aritimétrica: $14,2 \%$} \\
\hline
\end{tabular}

Os constituintes dissolvidos são primários, representados por feldspato ortoclásio e plagioclásio, quartzo monocristalino e outros grãos não identificados (Figura 8A). A porosidade por fratura está muito presente nos grãos de quartzo monocristalinos
(Fig. 8C), microclínio e plagioclásio (Figura 8B), mas também ocorre em fragmento de rocha. Foi também observada porosidade secundária por encolhimento de argila esmectita.
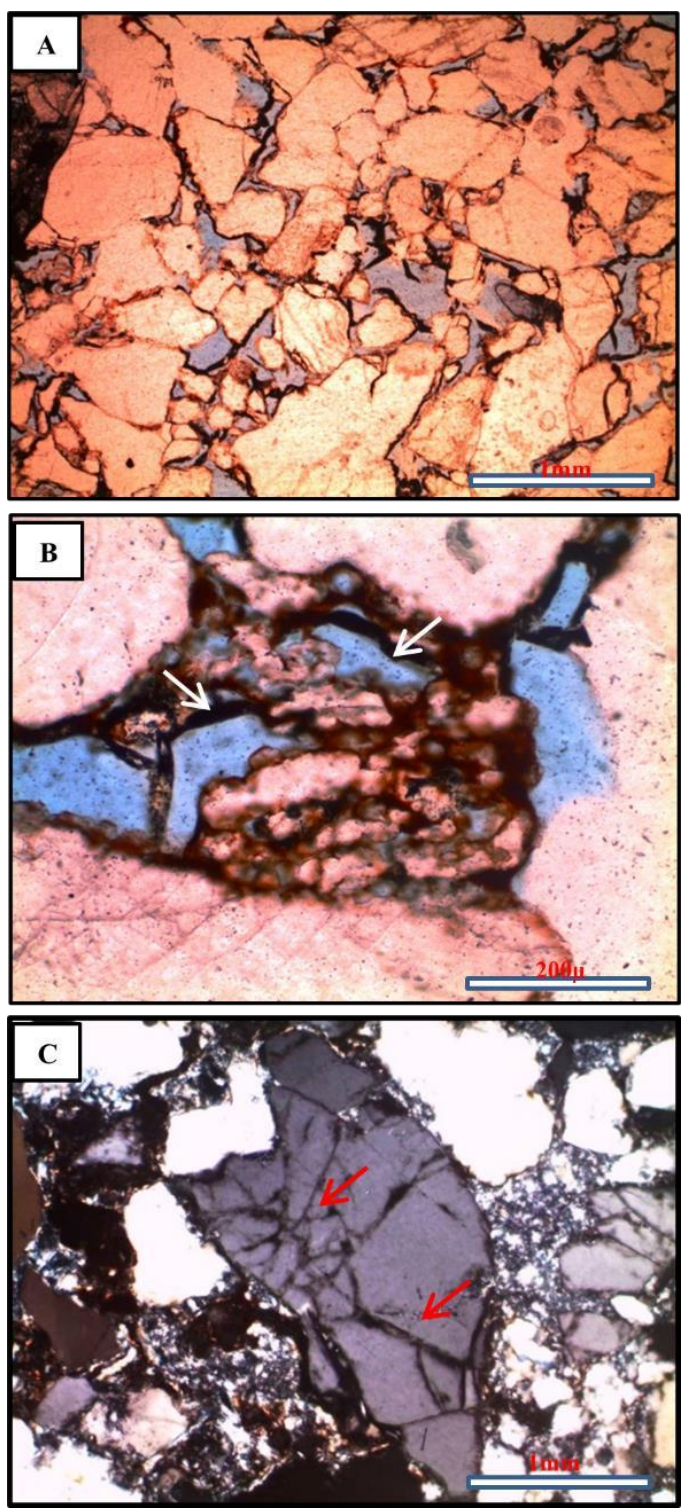

Figura 7 - Tipos de porosidade: A) Porosidade primária intergranular (cor azul, P//); B) Porosidade secundária de dissolução parcial de feldspato (setas, P//); e C) Porosidade secundária de fraturas de grão de quartzo ( setas, $P X$ ). 

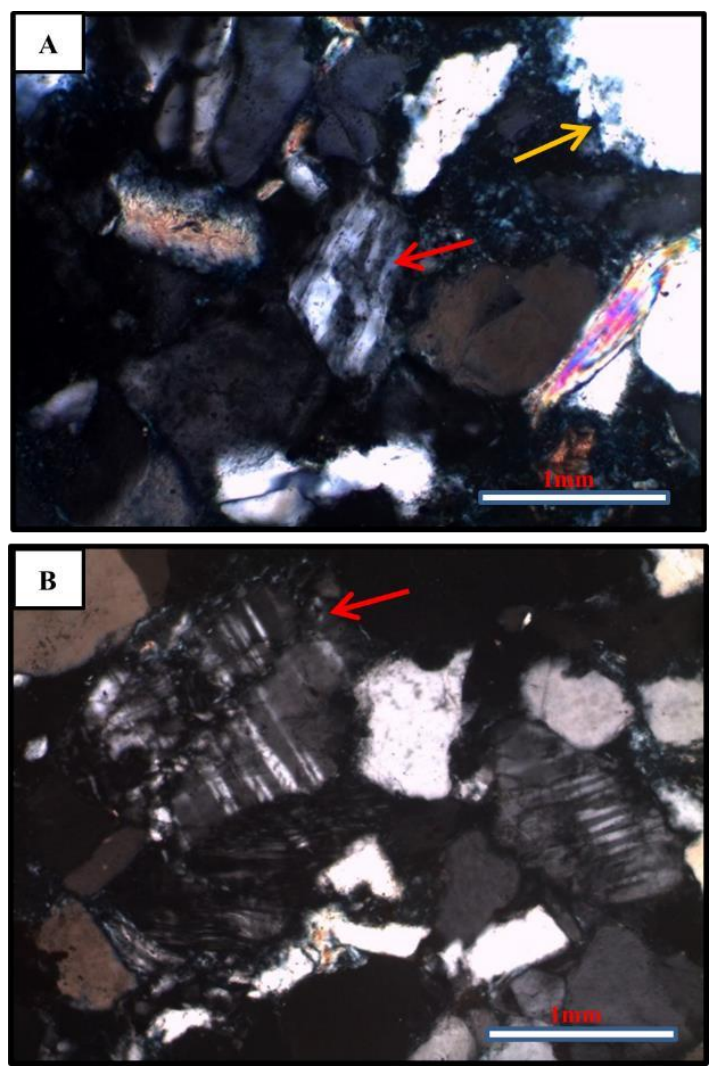

Figura 8 - Constituintes primários dissolvidos e fraturados: A) feldspato ortoclásio e grão de quartzo sofrendo dissolução (setas vermelha e amarela, respectivamente, $P X) ; \quad B)$ Grão de plagioclásio fraturado (seta, PX).

\subsection{Processos Diagenéticos}

\subsubsection{Infiltração Mecânica de Argila}

A argila infiltrada, processo da eodiagênese, ocorre na forma de cutículas envolvendo grãos de forma contínua e descontínua, como agregados microcristalinos intersticiais obstruindo boa parte da porosidade primária (Figura 9A e B), e na forma encolhida (shrinkage), originando porosidade secundária.

São introduzidas pelas águas de enchentes fluviais episódicas após longos períodos de estiagem. Com o lençol freático rebaixado, enxurradas carregadas de carga em suspensão passam sobre os sedimentos e grandes volumes de água infiltram-se nesses depósitos, graças à alta permoporosidade das areias, abastecendo o lençol freático (CAETANO-CHANG \& WU, 2003).

Análises ao MEV com o auxílio do WDS e da difratometria de raios-X revelaram que os argilominerais presentes nesses arenitos são essencialmente esmectita e, subordinadamente, caulinita, ilita (Figura 10 A e B), interestratificado de ilitaesmectita (Figura 9B) e traços de clorita.
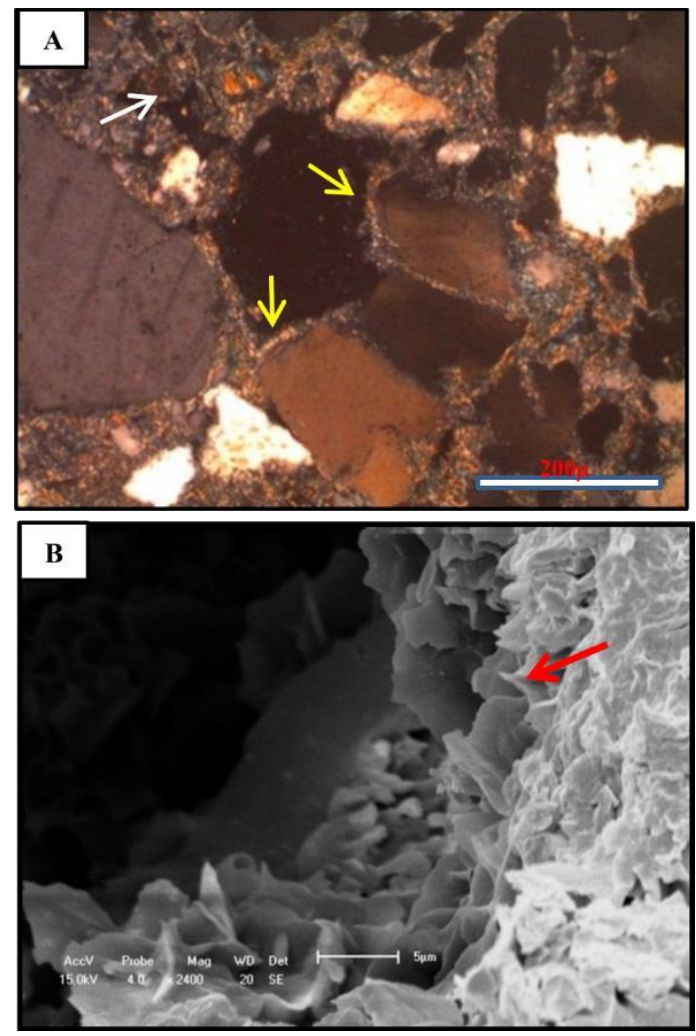

Figura 9 - Argila infiltrada: A) Cutícula de esmectita/ilita recobrindo grãos (setas amarelas) e como agregado microcristalino (seta branca) (PX); e B) Imagem de MEV ilustrando esmectita recobrindo grão (seta), com evidência de ilitização.

Na análise de DRX in natura a esmectiva foi detectada por reflexões de 16,08 $\AA$ (> pico) e 2,25 $\AA$ (< pico); traços de caulinita aparecem pelas reflexões de 7,4 $\AA$ (> pico) e 2,56 Ả (<pico). Após a glicolagem a esmectita apresentou um pequeno deslocamento, com reflexões de 17,0 Å. Foi também possível observar a presença de ilita com reflexão de $9,88 \AA$, que não apareceu no tratamento in natura.

A argila de encolhimento provavelmente é esmectita, pois apresenta feições de contração e descolamento, comuns em argilominerais hidratados como esse.

\subsection{Compactação}

A compactação mecânica nos arenitos analisados foi bastante atuante, originando faturamento de grãos rígidos (quartzo e feldspatos), deformação de grãos dúcteis formando pseudomatriz, e micas dobradas e abertas entre grãos do arcabouço (Figura 11A), além de empacotamento fechado em algumas amostras. Esse processo ocorre na eodiagênese e, para Worden et al (2000a), o resultado da forte compactação mecânica depende principalmente da proporção entre grãos rígidos e dúcteis.

A compactação química, processo da mesodiagênese que ocorre com maior soterramento, foi menos intensa que a mecânica, causando dissolução parcial de feldspato e quartzo no 
centro e bordas desses grãos e gerando porosidade secundária e contatos côncavo-convexos e suturados.

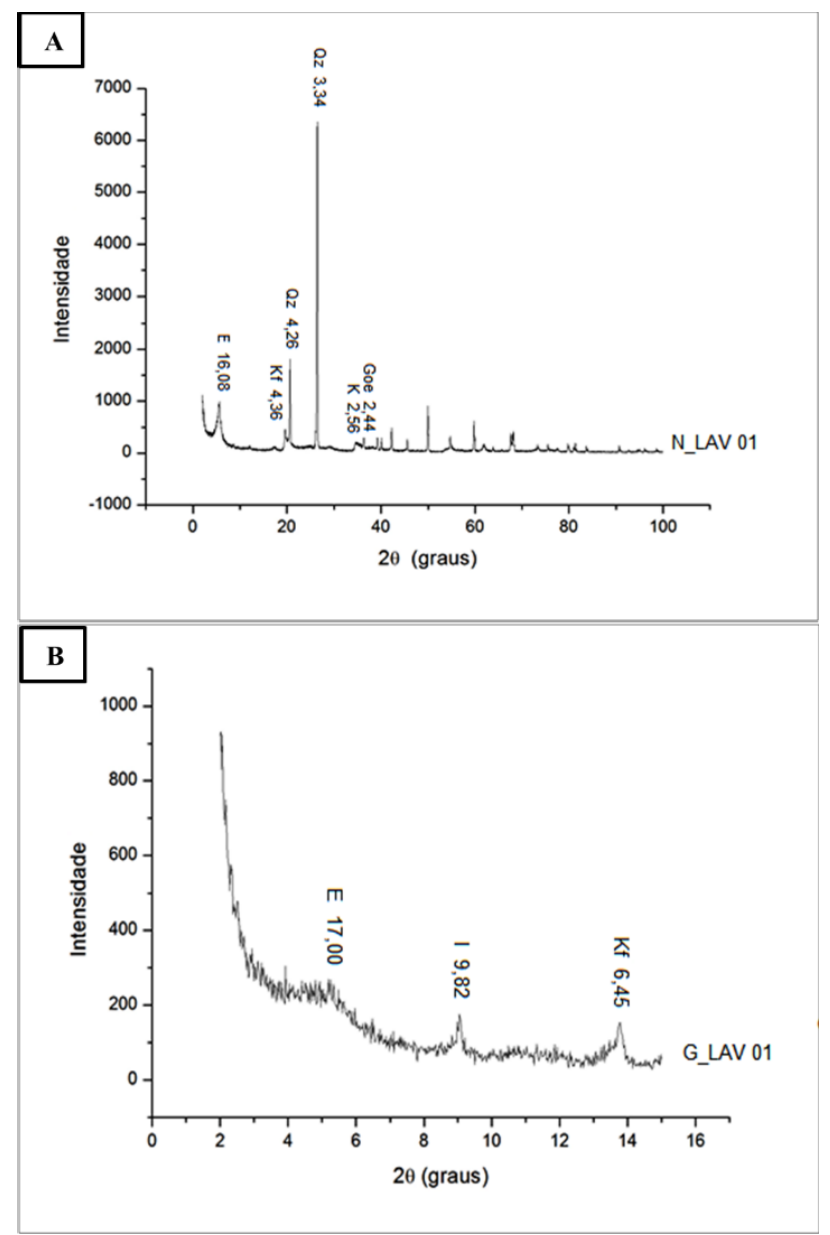

Figura 10 - Argilominerais: A) Análise de DRX sem tratamento (in natura); B) Análise de DRX com tratamento de glicolagem. Legenda: $Q z$-quartzo; Kf-feldspato; E-esmectita; I-ilita; $K$ - caulinita; Goe - goetita.

\subsection{Cimentação}

\subsection{1. Óxido/hidróxido de Ferro}

Esse cimento é o dominante e ocorre como finas cutículas (coatings) circundando os grãos. Subordinadamente, ocorre preenchendo poros intergranulares na maioria das amostras, e é típico da telodiagênese. Isso indica duas fases dessa cimentação ferruginosa: cutículas recobrindo grãos de quartzo no início da eodiagênese (1); precipitação desse cimento preenchendo os poros intergranulares na telodiagênese (2).
A difratometria de raios-X (Figura 10A) revelou que esse cimento é constituído de goetita, a qual geralmente forma-se em condições oxidantes, como produto de alteração de minerais de ferro (ex., hematita e biotita).

\subsubsection{Sílica Autigênica}

Na maioria dos arenitos analisados foi constadada cimentação por sílica autigênica com feição de crescimento secundário de quartzo (overgrowths) em torno de grãos de quartzo (Figura 11B), e na forma de projeções prismáticas (outgrowths) (Figura 11C). Esse crescimento ocorre de forma contínua e descontínua, sugerindo duas fases de cimentação: uma fase antes da compactação intensa, ainda na eodiagênese (provavelmente no final); e outra após a intensa compactação, na mesodiagênese (maior soterramento dos sedimentos).

\subsubsection{Precipitação de Caulinita, Esmectita e Clorita}

A caulinita foi identificada em algumas amostras e apresentase com hábito lamelar, na forma de agregados e como livrinhos (booklets) preenchendo poros integranulares. Sua precipitação está associada à dissolução de grãos de silicatos instáveis devido à circulação de fluidos intersticiais (na eodiagênese). Também ocorre substituindo minerais como muscovita e feldspato (KETZER et al., 2003).

A precipitação de esmectita ocorre de forma contínua e descontínua, como franjas circundando grãos, e pode estar relacionada a fluidos alcalinos e à presença de feldspato, muscovita e minerais pesados, fases susceptíveis a alteração para argilominerais durante a eodiagênese continental em condições de clima árido (KETZER, et al., 2003; MCKINLEY, et al., 2003; WORDEN \& MORAD, 2003).

A cimentação por clorita ocorre em algumas amostras preenchendo poros, de maneira pouco expressiva, e como produto de alteração e substituição de biotita. Esse cimento está associado à alteração de minerais ferromagnesianos e sua precipitação é comum na mesodiagênese (KETZER et al., 2003).

\subsection{Dissolução de Grãos}

Dissolução, principal geradora de prosidade secundária, é um processo no qual um mineral é destruído pela interação com um fluido, deixando para trás uma cavidade (WOLDEN \& BURLEY, 2003).

Nos arenitos analisados a dissolução foi relativamente significativa, ocorrendo principalmente nos constituintes primários (feldspato (Figura 12A), quartzo, micas e outros não distintos). Os feldspatos foram os mais atingido pela dissolução, mais frequente ao longo da clivagem e no centro dos grãos.

No geral, a dissolução foi predominantemente parcial e mais efetiva no centro dos grãos (Figura 12A), gerando porosidade secundária intragranuar e alargamento de poros. 

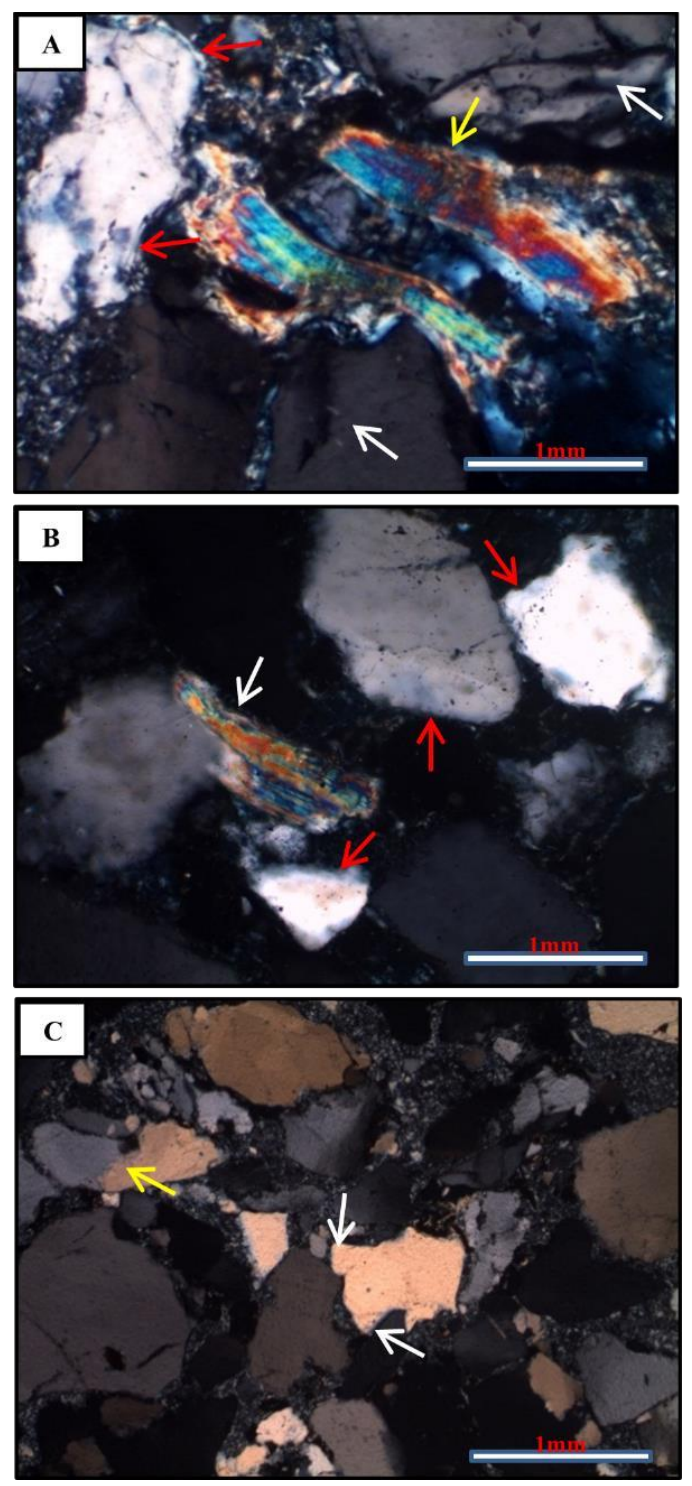

Figura 11 - Produtos Diagenéticos: A) Muscovita dobrada entre grãos de quartzo (seta amarela), grãos de quartzo fraturados (setas brancas), com dissolução e crescimento secundário (setas vermelhas) (PX); B) Crescimento secundário de quartzo (setas vermelhas) e muscovita entre grãos (seta branca) (PX); e C) Projeções prismáticas de quartzo (setas brancas), e contato suturado entre grãos de quartzo (seta amarela) (PX).

\subsection{Geração de Porosidade Secundária}

A porosidade secundária pode ser gerada por diversos fatores, como: dissolução parcial ou total de grãos instáveis do arcabouço da rocha (feldspatos e fragmentos líticos); fraturamento de grãos rígidos, quando submetidos a grandes pressões relacionadas ao soterramento dos sedimentos; e encolhimento de argilominerais, quando esses sofrem desidratação, resultando na perda do volume original.
Nesses arenitos a porosidade secundária varia de pequenos poros originados pelo fraturamento de grãos rígidos, como quartzo e feldspato (Figura 12B), à dissolução parcial de feldspatos (Figura 11A), além do encolhimento de argila (Figura 12C).
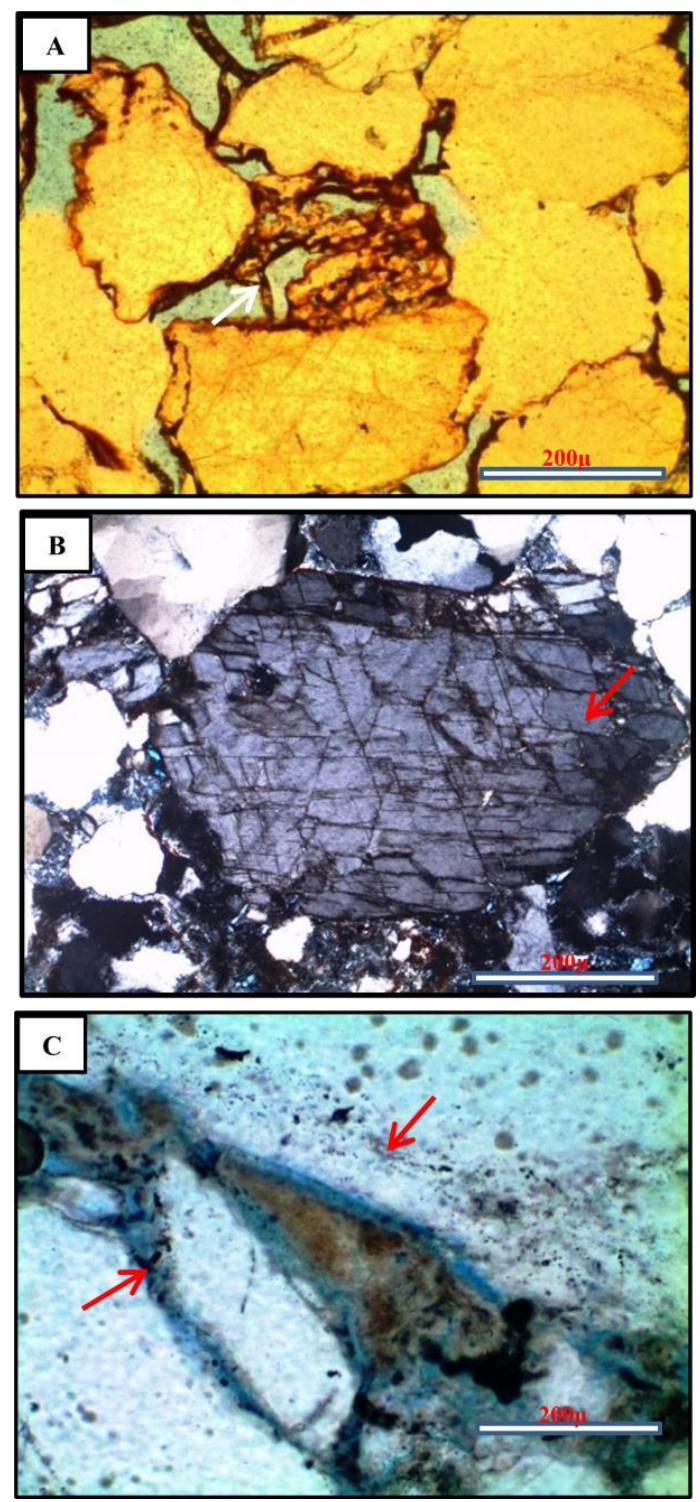

Figura 12 - Produtos diagenéticos: A) Feldspato parcialmente dissolvido, gerando porosidade secundária (seta, P//); B) Fraturamento de feldspato gerando porosidade secundária (seta, PX); e C) Encolhimento de argila (setas) gerando porosidade secundária $(P / /)$.

\subsection{Alteração e Substituição de Grãos}

Feições de alteração e substituição de grãos foram observadas no feldspato potássico e muscovita. Esses minerais frequentemente ocorrem alteradas e substituídas por caulinita e 
ilita (Figura 13A e B), os quais apresentam-se na forma expandida, lamelar e como franjas e cutículas circundando grãos de quartzo.

Também ocorre alteração e substituição de biotita para clorita, face ao aumento da instabilidade do argilomineral com o aumento da profundidade (COSTA et al., 2014).

É provável que a exposição dos feldspatos à eodiagênese e mesodiagênese tenha provocado a sua alteração, causando a dissolução parcial ou total, e/ou provocando sua caulinização total. A caulinização da muscovita foi reconhecida pela morfologia das terminações abertas, semelhantes a leques, além de lamelas separadas.
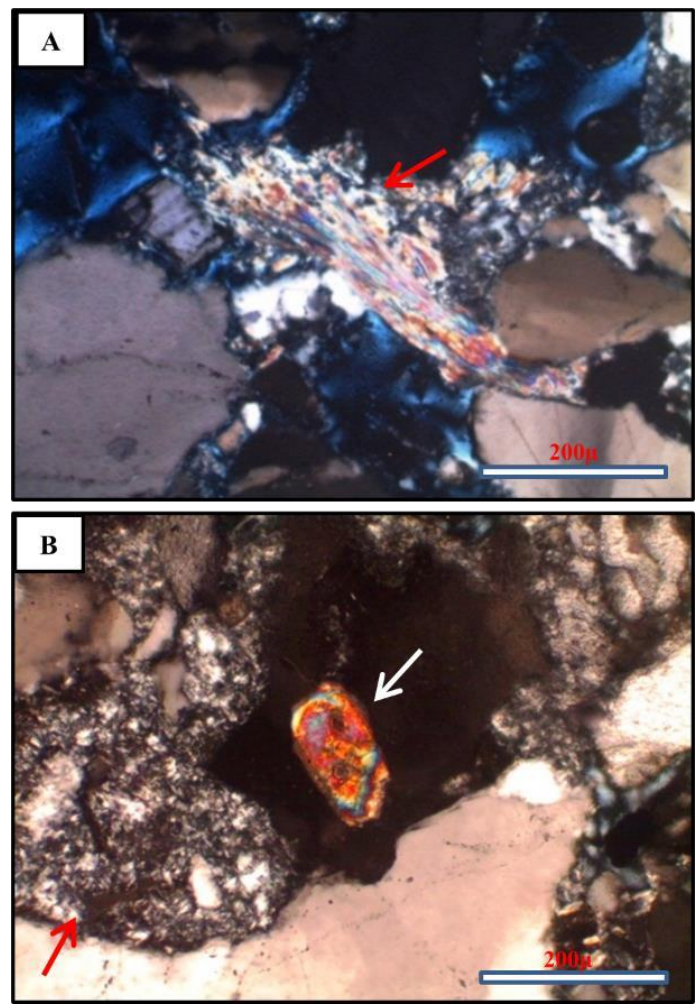

Figura 13 - Substituição de grãos primários: A) Substituição de muscovita por caulinita (seta, PX); e B) Substitução de feldspato por caulinita (seta vermelha, PX). Grão de zircão (seta branca).

\subsection{Discussão}

A composição mineralógica dos arenitos da Fm. Iborepi mostra-se rica em quartzo e pobre em feldspato e minerais pesados, provavelmente devido aos processos diagenéticos (alteração e dissolução de grãos primários instáveis e substituição por argilominerais), os quais modificaram sua composição original (gerando a predominância de quartzoarenitos).

Os processos diagenétios que mais atuaram e reduziram a porosidade primária desses arenitos foram compactação mecânica e química, cimentação, argila infiltrada e substituição de grãos.

A compactação foi o processo que mais atuou e impactou negativamente a porosidade primária desses arenitos. Grãos rígidos muito fraturados, deformação de grãos dúcteis, empacotamento fechado e contatos côncavo-convexos e suturados sugerem forte soterramento e compactação mecânica e química intensas, causando redução da porosidade original dessas rochas e do seu potencial como reservatórios de fluidos.

Segundo Worden et al (2018), processos de compactação na mesodiagênese são influenciados pela taxa de soterramento, pressão e história térmica da bacia.

A cimentação por óxido/hidróxido de ferro e sílica autigênica constitui o segundo processo diagenético que mais impactou a porosidade primária dos arenitos Iborepi. Em menor proporção, a perda da porosidade também ocorreu devido à cimentação por caulinita, esmectita e clorita.

A principal fonte de ferro para esses arenitos pode estar associada à dissolução de minerais ferromagnesianos, como a biotita e hematita.

O cimento de quartzo é o que mais destrói a porosidade de arenitos fortemente soterrados (Worden \& Morad 2000; Chudi et al., 2016) e aumenta de forma constante, à medida que a profundidade aumenta (CHUDI et al., 2016). Este tipo de cimento tende a cristalizar com o tempo, temperatura e tamanho do grão (WORDEN et al., 2018).

A argila infiltrada ocorre predominantemente na forma de agregados microcristalinos, destruindo boa parte da porosidade original desses arenios, e, consequentemente, diminuindo seu potencial como reservatórios de fluidos.

Nos arenitos Iborepi é muito comum a substituição de feldspato e muscovita por caulinita. A muscovita caulinizada apresenta-se principalmente na forma expandida e em lamelas, indicando que sua expansão ocorreu antes da compactação significativa (KETZER et al., 2003; MORAD et al., 2010). A substituição de grãos micáceos causou aumento no seu volume, obstruindo e diminuindo a porosidade primária da rocha.

A escassez de fragmentos líticos, feldspatos e minerais instáveis como anfibólio, piroxênio, entre outros, sugere que esses grãos foram dissolvidos pela percolação de águas meteóricas sub-saturadas (Morad, et al., 2000) na telodiagênese.

A reação dos feldspatos potássicos com água meteórica pode ter gerado, além da dissolução, sua substituição por caulinita. De acordo com Morad et al (2000), em sedimentos fluviais proximais a percolação de águas meteóricas sub-saturadas provoca a dissolução de silicatos detríticos, principalmente grãos líticos, feldspatos e micas, e a precipitação de caulinita.

Entre os componentes dos arenitos estudados, grãos de feldspato foram os mais susceptíveis à dissolução parcial (BHUIYAN \& HOSSAIN, 2020).

A petrografia mostrou que a porosidade dos arenitos da Fm. Iborepi foi mais afetada pelo processo de compactação que pelo de cimentação. Por outro lado, a porosidade foi mais prejudicada pelo efeito da cimentação que pela infiltração de argila.

Vale ressaltar que a redução de porosidade por compactação

apresenta um aspecto irreversível, tanto no tamanho como na geometria dos poros. A cimentação, por sua vez, pode atuar na preservação do arcabouço durante o soterramento e posteriormente favorecer um ganho de porosidade por dissolução. A composição detrítica dos arenitos estudados também influenciou a redução da sua porosidade (Rodrigues \& Goldberg, 2014), pois arenitos com grãos micáceos têm maior redução de porosidade devido à compactação mecânica. Além disso, muitos 
são substituídos por caulinita, obliterando a porosidade (RODRIGUES \& GOLDBERG, 2014).

\section{CONSIDERAÇÕES FINAIS}

A composição original dos arenitos da Formação Iborepi foi bastante modificada por processos diagenéticos, resultando em rochas predominantemente quartzosas.

Compactação mecânica e química, cimentação ferruginosa, sílica autigênica, cimentação de caulinita, franjas de esmectita (que, em gargantas de poros pode ter diminuido a conexão entre eles), e infiltração de argila foram os processos diagenéticos que mais afetaram a porosidade primária desses arenitos e, consequentemente, sua qualidade como reservatório de fluidos. Contudo, a porosidade foi destruída predominantemente pela compactação.

Estes processos foram responsáveis pelo dano à porosidade e permeabilidade face à redução do espaço poroso e obliteração da garganta dos poros. Ademais, a perda da porosidade intergranular também ocorreu devido à substituição de grãos como feldspato e micas.

Os produtos diagenéticos oriundos desses processos agiram como barreiras diagenéticas ao fluxo de fluidos, gerando heterogeneidades na rocha reservatório.

A análise petrográfica revelou que a composição detrítica também influenciou na alteração da porosidade original dos arenitos Iborepi, visto que alguns constituintes primários instáveis foram dissolvidos, gerando cimento, enquanto outros foram substituídos.

Apesar de conter uma porosidade razoável para armazenamento de fluidos (média de 14\%), os processos diagenéticos nos arenitos Iborepi impactaram sua qualidade como reservatório.

\section{REFERÊNCIAS}

AL-RAMADAN, K; MORAD, S.; PROUST, J.N.; AL-AASM, I.S. Distribution of diagenetic alterations within the sequence stratigraphic framework of shoreface siliciclastic deposits: evidence from Jurassic deposits of ne France. Journal of Sedimentary Research, v. 75, p. 943-959, 2005.

ASSINE, M.L. Análise Estratigráfica da Bacia do Araripe, Nordeste do Brasil. Revista Brasileira de Geociências. v. 22, n. 3, p.298-300, 1992.

BATISTA, Z.V.; QUEIROZ, L.F.; AGOSTINHO, S.M.O. Petrofácies Deposicionais dos Arenitos da Formação Iborepi, Bacia de Lavras da Mangabeiras. In: CONGRESSO TÉCNICO CIENTÍFICO DA ENGENHARIA E DA AGRONOMIA (CONTECC) E $75^{\mathrm{a}}$ SEMANA OFICIAL DA ENGENHARIA E DA AGRONOMIA (SOEA), 2018, Maceió - AL. Ciência, Inovação e Tecnologia. Campina Grande - PB: epgraf, 2018.

BATISTA, Z.V. Caracterização faciológica, petrográfica $e$ diagenética das sequências basais das bacias do Parnaíba, Araripe, São José do Belmonte e Lavras da Mangabeira: contribuição às possíveis correlações dos arenitos basais e suas implicações geotectônicas. 2015. 236f. Tese (Doutorado em Geociências). Programa de Pós-Graduação em Geociências, Universidade Federal de Pernambuco, Recife-PE, 2015.

BHUIYAN, A.H.; HOSSAIN, S. 2020. Petrographic characterization and diagenetic evolution of reservoir sandstones from Smørbukk and Heidrun fields, offshore Norway. Journal of Natural Gas Geosciences, 5, 11-20. Online $27 \quad$ January 2020. https://www.keaipublishing.com/jnggs.

BRITO NEVES, B.B., SANTOS, E.J., AND VAN SCHMUS, W.R. Tectonic history of the Borborema province, northeastern Brazil, in Cordani, U. G. et al., eds., Tectonic evolution of South America, 31ST INTERNATIONAL GEOLOGICAL CONGRESS. p. 151-182, 2000.

CAETANO-CHANG, M.R., WU, F.T. Diagênese de arenitos da Formação Pirambóia no Centro-Leste Paulista. UNESP, Revista Geociências, v. 22, n. especial. São Paulo. p. 33-39, 2003.

CHUDI, O.K.; LEWIS, H.; STOW, D.A.V. \& BUCKMAN, J.O. Reservoir quality prediction of deep-water Oligocene sandstones from the west Niger Delta by integrated petrological, petrophyscial and basin modelling. In: Armitage, P.J., Butcher, A. et al. (eds) Reservoir Quality of Clastic and Carbonate Rocks: Analysis, Modelling and Prediction. Geological Society, London, Special Publications, 435. First published online December 14, 2016, https://doi.org/10.1144/ SP435.8.

CESERO, P.; MAURO, L.M.; DE ROS, L.F. Técnicas de preparação de lâminas petrográficas e de moldes de poros na Petrobrás. Boletim de Geociências da Petrobrás, n.3, p. 105$116,1989$.

COSTA, A.B.S.; CÓRDOBA, V.C.; JARDIM DE SÁ, E.F.; SHERER, C.M. Diagênese dos arenitos da tectonossequência rifte na Bacia do Araripe, NE do Brasil. Brazilian Journal of Geology, v. 44, n. 3, p. 457-470, 2014.

FOLK, R.L. Petrology of sedimentary rocks. Hemphill Publishing Company, Austin, TX, USA. 1974. 182p.

FOLK, R.L. Petrology of sedimentary rocks. Austin, Texas, Hemphill's, Pub., 1968. 107p.

FOLK, R. L. Stages of Textural Natury in Sedimentary Rocks. 1951. Journal of Sedimentary Petrology, 21, 127-130.

GESICKI, A. L. D., SAYEG, I. J., CURTI, D. K, BOGGIANI, P. C., GIANNINI, P. C. F. Determinação quantitativa de parâmetros texturais de arenitos eólicos através de análise de imagens digitais de seções delgadas. 2009. Revista Brasileira de Geociências, 39 (2): 267-275.

GRANJEIRO M.L.; SANTIAGO, M.M.F.; FRISCHKORN, H.; VIDAL SILVA, C.M.S.; MENDES FILHO, J. Influência do Ambiente Sedimentar na Qualidade das Águas Subterrâneas 
da Bacia Sedimentar no Município de Lavras da Mangabeira, Ceará. In: XV CONGRESSO BRASILEIRO DE ÁGUAS SUBTERRÂNEAS. Natal. 2008.

KAHN, J.S. The analysis and distribuition of the proprerties of packing in sand size sediments. Journal Geology, v. 64, n.4, 385-395, 1956.

KETZER, J.M.; MORAD, S.; AMOROSI, A. Predictive diagenetic clay-mineral distribution in siliciclastic rocks within a sequence stratigraphic framework. In: Clay Mineral Cements in Sandstones, International Association of Sedimentologists Special Publication 34 (Ed. by R.H. Worden and S. Morad), Blackwell Publishing, Oxford, p. 43-61, 2003.

LONGIARU, S. 1987. Visual Comparators for Estimating the Degree of Sortting from Plane and Thin Section. Journal of Sedimentary Petrology, 57, 791-794.

Matos, R.M.D. History of the Northeast Brazilian Rift System: Kinematic implications for the breakup Brazil and West Africa. In: Cameron, N.R., Bate, R.H., Clure, V.S. (eds.). The oil and gas habitats of the South Atlantic. Geological Society of London, Special Publications, London, v. 153, p.55-73, 1999.

Matos R.M.D. The Northest Brasilian Rift System. Tectonics, v. 11, p. 776-791, 1992.

MCKINLEY, J.M.; WORDEN, R.H.; RUFFELL, A.H. Smectite in sandstones: A review of the controls on occurrence and behaviour during diagenesis. in: Worden, R. H., Morad, S. (Eds.), Clay Cements in Sandstones. International Association of Sedimentologists Special Publications, Blackwell Scientific Publications, Oxford, UK, n. 34, p. 109-128, 2003.

MORAD, S.; KETZER, J.M.; DE ROS, L.F. Linking diagenesis to sequence stratigraphy: an integrated tool for understanding and predicting reservoir quality stribution. In: Morad, S.; Ketzer, J. M.; De Ros, L. F. Linking Diagenesis to Sequence Stratigraphy. IAS Special Publication 45. Chichester, UK: International Association of Sedimentologists. Wiley-Blackwell, p.1-36. 2012.

MORAD, S.; AL-RAMADAN K., KETZER, J.M. \& DE ROS, L.F. The impact of diagenesis on the heterogeneity of sandstone reservoirs: a review of the role of depositional facies and sequence stratigraphy. American Association of Petroleum Geologists Bulletin, v. 94, 1267-1309, 2010. https://doi.org/10.1306/04211009178.

MORAD S., KETZER .J.M.; DE ROS L.F. Spatial and temporal distribution of diagenetic alterations in siliciclastic rocks: implications for mass transfer in sedimentary basins. Sedimentology, v. 47. 1-27, 2000.

MORAES, M.A.S.; SURDAM R.C. Diagenetic heterogeneity and reservoir quality: fluvial, deltaic, and turbiditic sandstone reservoirs, Potiguar and Reconcavo rift basins, Brazil: AAPG Bulletin, v. 77, p. 1142-1158, 1993.

PETTIJOHN, F.J. Sedimentary Rocks, 3rd Ed., 1975. 628p.

PONTE, F.C.; DINO, R.; ARAI, M. E SILVA-TELLES JR. A.C. DA. Geologia das bacias sedimentares de Lavras da Mangabeira e do remanescente sedimentar do Rio dos Bastiões, no Estado do Ceará, Petrópolis, RJ, 1990. PETROBRAS-CENPES-DIVEX-SEBIPE.

POSAMENTIER, H.W; ALLEN, G.P. 1999. Siliciclastic sequence stratigraphy concepts and applications. SEPM, 1999, n. 7, 216p.

POWERS, M. C. 1953. A new roundness scale for Sedimentary Particles. Journal of Sedimentary Petrology, 23, 117-119.

QUEIROZ, L.F.; BATISTA, Z.V.; LIMA FILHO, M.F. Caracterização Petrográfica e Diagenética dos Arenitos da Formação Iborepi, Porção Sul da Bacia de Lavras da Mangabeira. In: $9^{\circ}$ CONGRESSO BRASILEIRO DE P\&D EM PETRÓLEO E GÁS, 2017, Maceió-AL, 2017. v. 5. p. 222-229.

RODRIGUES, A.G.; GOLDBERG, K. Primary composition and diagenetic patterns of sandstones from Barra de Itiúba Formation in Atalaia High, Sergipe Sub-Basin. Brazilian Journal of Geology, v. 44, n. 4, p. 545-560, 2014.

ROSSI, C.; MARFIL, R.; RAMSEYER, K.; PERMANYER, A. Facies-related diagenesis and multiphase siderite cementation and dissolution in the reservoir sandstones of the khatatba formation, gypt's western desert. Journal of Sedimentary Research, v. 71, p. 459-472, 2001.

TEIXEIRA, W.; TOLEDO, M.C.M. DE; FAIRCHILD, T.R.; TAIOLO, F (Orgs.). Decifrando a Terra. Oficina de textos. São Paulo. 2003. 558p.

VERÍSSIMO, L. S. \& AGUIAR, R. B. Comportamento das bacias sedimentares da região semi-árida do Nordeste brasileiro. Hidrogeologia da bacia sedimentar de Lavras da Mangabeira. Fortaleza: CPRM/FINEP, 2005. 36 p. il.

WARSHAW, C.; ROY, R. Classification and scheme for the identification of layer silicates. Geological Society of America Bulletin, v. 72, 1455-1492, 1961.

WENTWORTH, C. K. 1922. A scale of grade and class terms for clastic sediments. Journal Sedimentary Petrology, 30, 377392.

WORDEN, R.H.; ARMITAGE, P.J.; BUTCHER, A.R.; CHURCHILL, J.M.; CSOMA, A.E.; HOLLIS, C.; LANDER, R.H.;OMMA, J.E. 2018. Petroleum reservoir quality prediction: overview and contrasting approaches from sandstone and carbonate communities. In: ARMITAGE, P.J.; BUTCHER, A.R.; CHURCHILL, J.M.; CSOMA, A.E.; HOLLIS, C.; LANDER, R.H.; OMMA, J.E. \& WORDEN, R.H. (eds.). Reservoir Quality of Clastic and 
Carbonate Rocks: Analysis, Modelling and Prediction. London: Geological Society, Special Publications, 435. First published online 01, 2018, http://doi.org/10.1144/SP435.21.

WORDEN, R. H. \& MORAD, S. Clay minerals in sandstones: controls on formation distribution and evolution. In: Worden, R. H. \& Morad, S. (Eds.). Clay minerals cements in Sandstones, International Association of Sedimentologists Special Publication 34 (Ed. by R.H. Worden and S. Morad), Blackwell Publishing, Oxford, p. 109-128, 2003.

WORDEN, R.H. \& BURLEY, S.D. 2003. Sandstone diagenesis: the evolution from sand to stone. In: Burley, S.D. \& Worden, R.H. (eds) Sandstone Diagenesis, Recent and Ancient. International Association of Sedimentologists Reprint Series, Oxford, 3-44.
WORDEN, R.H., MAYALL, M.J. \& EVANS, I.J. The effect of ductile-lithic sand grains and quartz cement on porosity and permeability in Oligocene and Lower Miocene clastics, South China Sea: prediction of reservoir quality. American Association of Petroleum Geologists Bulletin, 84, 345-359, 2000a.

WORDEN, R.H. \& MORAD, S. 2000. Quartz cementation in sandstones: a review of the key controversies. In: Worden, R.H. \& Morad, S. (eds) Quartz Cementation in Sandstones. International Association of Sedimentologists, Special Publications, oxford, 1-20.

ZUFFA, G.G. Optical analysis of arenites: influence of methodology on compositional results. In: Zuffa G.G. (ed.). Provenance of Arenites. Dordrecht, Germany, D. Reidel Pub. Co. 1985. p.165-189.

Recebido em: 21/08/2021

Aceito para publicação em: 15/10/2021 